Document downloaded from:

http://hdl.handle.net/10251/49590

This paper must be cited as:

Alfaro Saiz, JJ.; Carot Sierra, JM.; Rodríguez Rodríguez, R.; Jabaloyes Vivas, JM. (2011). Seeking organisational excellence by using the information coming from the EFQM excellence model as starting point: application to a real case. Total Quality Management and Business Excellence. 22(8):853-868. doi:10.1080/14783363.2011.597595.

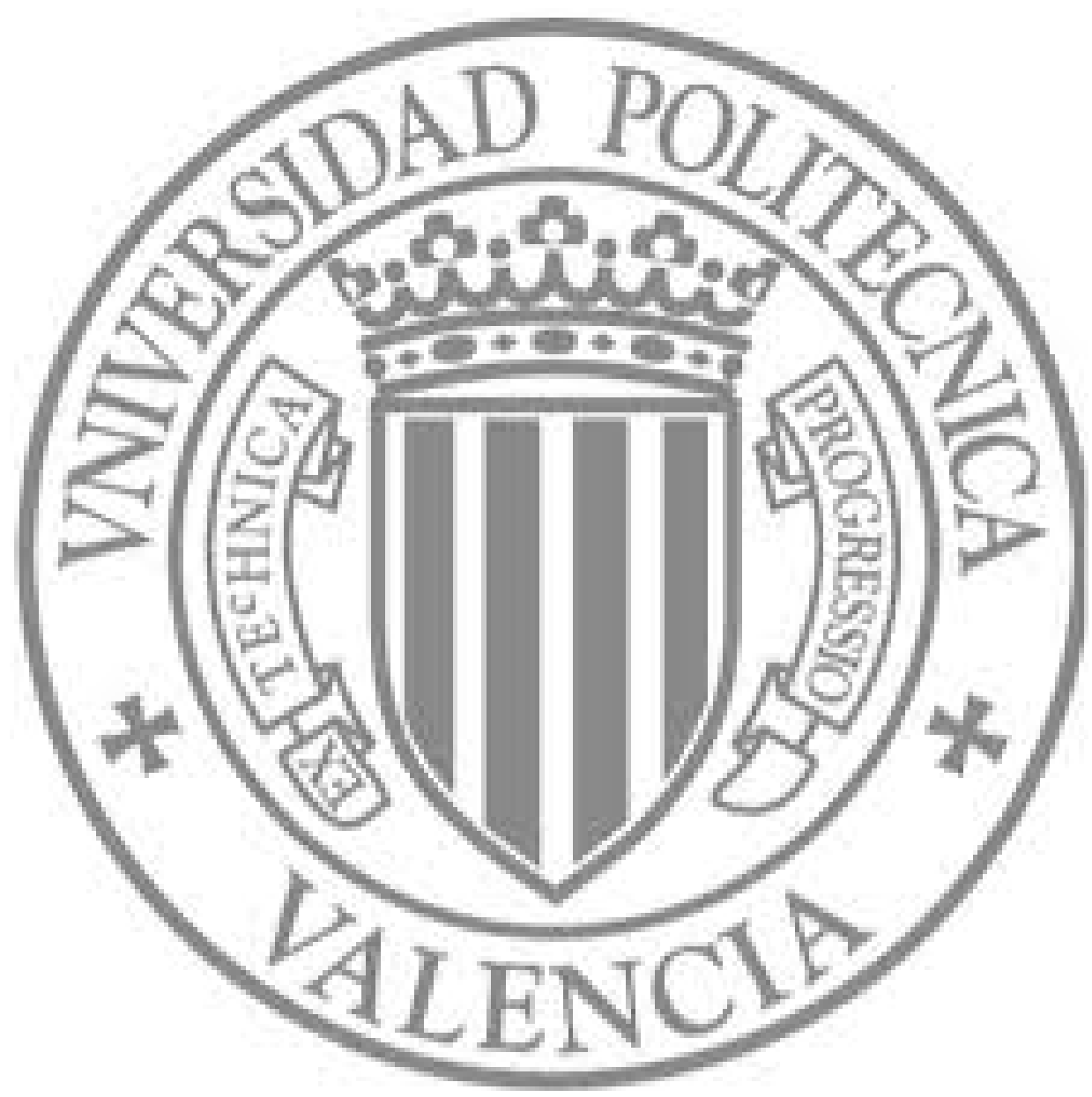

The final publication is available at

http://dx.doi.org/10.1080/14783363.2011.597595

Copyright Taylor \& Francis 


\title{
Seeking organisational excellence by using the information coming from the EFQM excellence Model as starting point. Application to a real case
}

\author{
JJ. Alfaro*, J.M Carot**, R. Rodríguez* \& J.M. Jabaloyes** \\ * Research Centre on Production Management and Engineering, Polytechnic \\ University of Valencia, Spain; ** Department of Statistics and operations research, \\ Polytechnic University of Valencia, Spain \\ Correspondence Address: JJ. Alfaro, Department of Business Administration, \\ Polytechnic University of Valencia, 46022 Camino de vera S/NE, Valencia (Spain) \\ Email: jalfaro@omp.upv.es
}

\begin{abstract}
This paper describes how to use the information coming from applying the EFQM excellence model to analyse the perception that the members of an organisation keep of it regarding its business vision. Such an analysis is made in base to the EFQM excellence model criteria and by applying statistical data analysis techniques. With this study, besides to detect both the strong and weak areas of actuation on which an organisation should focus and act, it is possible to also detect the relationships between the personal characteristics of members of the organisation and their business vision. Then, the main goal is that organisations are able to reach the excellence by jointly using an assessment method (the EFQM excellence model) and posterior statistical data analysis techniques (uni-variant and multi-variant). These techniques enable to complement and enlarge the potential of the EFQM excellence model. Finally, the procedure is illustrated by presenting the main results of applying it to a real case of the Permanent Training Centre of the Polytechnic University of Valencia in Spain.
\end{abstract}

Keywords: excellence model; business vision; data analysis

\section{Introduction}

From the creation of the EFQM at the end of the 80 s and posterior apparition $f$ the EFQM excellence model, many organisations have available a framework to assess their performance. The self-assessment approach presented in the EFQM excellence model allows measuring the situation in which an organisation is in relation to the aimed excellence position. Therefore, this model can clearly be used as an instrument to acquire and keep a leader position if it is properly implemented. From a more detailed point of view, organisations use the EFQM excellence model to identify lacks within their different business processes. It is possible then to foster elements and improvement initiatives throughout all the areas and departments. Other organisations 
also use the EFQM excellence model as a part of their basic management structure, helping to define the organisation's strategic planning and to direct the board towards an excellence searching.

However, all the information that the EFQM excellence model provides to the management of organisations is not fully exploited, as it does have a much higher potential. This occurs because of different reasons. Firstly, due to the fact that the application of the EFQM excellence model itself is, sometimes, carried out by people who are not experts on the model, limiting their activity to assess the organisation without searching for a true integration of the model and future management of the organisation in a dynamic and smooth manner. Secondly, the information provided by the EFQM excellence model might be treated to seek both positive and negative aspects that are hidden in advance. Such aspects are important regarding organisational, competitive or labour aspects, which may facilitate the planning of improvement actions and to drive the organisation towards the business excellence. This treatment of the information needs that organisations have qualified personnel to carry it out.

Finally, to point out that there are not relevant works in the literature that cope with this type of information treatment within the EFQM excellence model context. Nor are there works that allow standardising procedures to be used within the daily organisational ambit. In this sense, the present paper describes how to goes beyond the classic application of the EFQM excellence model by using statistical data techniques to further analyse the information collected by the model. Suitable techniques to be used are described in the application later on the text. The next point briefly and critically revises the basis of the EFQM model. Then, the main advantages of using statistical techniques to seek for latent information in databases are 
highlighted. Such latent relationships may serve to improve and complement the characteristic of such a model. The main results of applying these techniques to a real case are then presented. Finally, the main conclusions are established.

\section{The EFQM excellence Model as starting point}

The EFQM model has been widely treated within the literature from different approaches. Then, it appears in multiple research articles, books, etc. and it has also been implemented in all types of organisations from production/services enterprises to government ones. From its launching in 1991, the Governing Committee of EFQM has improved the EFQM model after several meetings. Initially, the EFQM model represented for lots of authors an evolution of the Total Quality Management (TQM) concept towards the called Business Excellence. Authors such as Dale, Zairi, Van der Wiele, \& Williams, (2000) do not agree on its name at the same time that work on the contextualisation of the concept under the connection TQM-EFQM. It is also possible to find authors that link the EFQM model to the performance management ambit. For Wongrassamee, Gardiner, \& Simmons, (2003) the specific purpose of the EFQM Excellence Model is to provide a systems perspective for understanding performance management. In this sense, some authors (Olve \& Wetter, 1999; Wongrassamee et al. 2003) have critically compared the EFQM model with the most performance measurement system, the Balanced Scorecard (Kaplan \& Norton, 1996). The main conclusion driven from these comparisons is that, even though the EFQM model is more focused on the TQM philosophy whereas the Balanced Scorecard aligns the strategy and deploys it all over the organisation, both models count with a structure that contains lots of similitude elements.

In the last years, it is aimed to link the EFQM model with some emergent disciplines such as information systems or knowledge management. In this sense, for 
Martin-Castilla \& Rodriguez-Ruiz (2008), the intellectual capital perspective is a key element that runs horizontally across the criteria of the EFQM excellence model. By this reason, they define and search the relations between several EFQM criteria and the components of intellectual capital. Thus, this model may be considered as tool for the governance of knowledge. Authors like Ruiz-Carrillo, J.I.C. \& Fernandez-Ortiz R. (2005) have analysed the usefulness of the EFQM model to identify the most representative resources and capabilities of the enterprise that allow us to identify what part of its structure generates the key resources to create competitive advantages. However, the EFQM model has also received numerous critics. As Rusjan (2005) claims, the EFQM Excellence Model is appropriately structured to perform the identification of the problematic situation (description of the present situation and identification of deviations of the present situation from benchmarks), however, the model does not offer any specific guidelines for problem identification (it offers no structured approach to exploiting strengths, or classifying and prioritizing areas of improvement). For Wongrassamee et al. (2003) the excellence model does not give any suggestion on what strategies or plans should be adopted in order to achieve continuous improvement, simply provides guidance about what areas will be examined under the European Quality Award scoring system. Baxter \& MacLeod (1999) state that the EFQM sub-criteria seem too superficial and the measurement process imprecise. Most of the critics focus on the weights structure, the scoring system and the definition of the criterion (Eskildsen, Kristensen, \& Juhl, 2001; Yang, Dale, \& Siow, (2001); Li \& Yang, 2003, Franceschini et al., 2007).

Li \& Yang (2003) warn that although the current scoring system of the EFQM model has been widely accepted by both academics and practitioners as a sound approach for self-assessment, there are some authors that point out that the scoring 
criteria are too generally defined, and therefore some organizations have encountered problems when applying the model. For Franceschini et al. (2007), from a conceptual point of view, the definition of each criterion is not transparent enough and the evaluation procedures may be differently interpreted.

Finally, there are several works that focus on analysing the relationships between diverse EFQM model components, the criteria and other environmental factors. Then, the body of literature that analyzes the relationship between quality management and organizational performance resorting to quantitative data analysis, and adopting a comprehensive analysis of the EFQM quality practices and outcomes, is limited (Santos-Vijande \& Alvarez-Gonzalez, 2007).

Even though these authors present a study that employs structural equations modeling (SEM) to test the criteria relationships, the employment of methodologies that allow evaluating causal relationships between enablers and results is scarce (BouLlusar, Escrig-Tena, Roca-Puig, \& Beltrán-Martín, 2005). For Rusjan (2005), the key in using the EFQM assessment model is to identify the relationship between the levers, between the goals, as well as between the levers and the goals, which leads to difficulties in the use of the self-assessment results.

Despite the described critics, the EFQM model is one of the most used models in practice by organisations to identify lacks in the organisations' processes. It enables the searching of improvement elements and initiatives through all the areas and/or departments. The information provided by a proper implementation of the EFQM model is very important and it may be used to discover multitude of a priori hidden factors, which facilitate the understanding of the organisation itself. Therefore, the EFQM model helps organisations in their decision-making processes but it can be improved as it is presented in this paper. 
On the other hand, there are several works (McAdam \& Welsh, 2000; Farrar, 2000; Hides, Davies, \& Jackson, 2004; Calvo \& Mora, 2006; Tarí, 2006) that focus on the educational ambit (where the practical example will take place).

The next point describes how to use the information coming from the application of the EFQM model to a Centre of Permanent Training (CPT) of the Polytechnic University of Valencia (Spain). It analyses the perception that have the members of such an organisation related to the business vision that they form part of. This analysis is made following the EFQM model criteria and by applying statistical data analysis techniques.

When having a set of data obtained by observing a certain phenomenon, it is necessary to have available effective tools to extract from such data relevant information that facilitate decision-making processes. The statistical techniques for data analysis enable to extract such information objectively. In the case presented in this work the data observed are of multivariate nature, in other words, an individual provides data about different variables. In many occasions, the analysis of these types of data matrices is carry out by studying the variables individually. Such a procedure, that is a necessary step in data analysis, provides only partial information. The multivariate analysis statistical techniques enable to extract much more enriched information as they take into account all the variables simultaneously (Anderson, 1984). The multivariate techniques have been widely applied to several fields of knowledge such as engineering, chemistry, medicine, management or economy (Timm, 2002).

\section{Case Study}

This case study follows the next phases: 
Phase 1: Application of the EFQM model. Self-assessment with the EFQM model to obtain the matrix with the values (numerically expressed) of each one of the model's sub-criteria (where the rows are each one of the individuals of the CPT and the columns each one of the sub-criteria).

Phase 2: Application of statistical data analysis techniques. Apart from an exhaustive uni-variant analysis applied to each one of the criteria and sub-criteria, the application of multi-variant statistical techniques is of special interest. In the latter case, it will be used the Principal Component analysis (PCA).

Phase 3: Analysis of results obtained in Phase 2. The results should help to assess the perception of all the CPT members. These results should point out not only the detection of strong areas of the CPT but also the relationships between the personal characteristics of the CPT members and their respective business vision. The considered characteristics are: work category, department or work group and activity.

\section{Description of the organization}

The Center of Permanent Training (CPT) is an organisation inside the Polytechnic University of Valencia (UPV) located in Valencia, Spain. It was created in 1991 with the general objective of "be an interface between the university and its environment regarding permanent training". Some of the specific objectives of the CPT are the following:

- To collaborate with the different departments and centers of the UPV to create and develop formative products and spreading such products to the UPV social-economic environment.

- To analyse the external social demand by transferring the detected formative needs to the autonomic government as well as to promote an agile and flexible answer. 
- To carry out a follow-up of the formative courses in process, of their docent adequacy.

- To carry out administrative tasks of the courses launched.

At the end of the year 2000 an internal re-organisation took place moving towards a process-oriented approach. During this period the mission, vision and objectives of the CPT are also redefined. From this moment, the CPT starts to involve to all its personnel through the carrying out its first self-assessment, being the participation of a $90 \%$. The CTP assumes the EFQM excellence model as the reference model for implementing the quality system, creating a window to the external environment in order to able to compare and interchange both experiences and best practices.

\section{Phase 1: Application of the EFQM model}

The self-assessment can be made by applying different tools regarding the degree of maturity of the organisation (see Table I). In this sense, the CPT is an entity with an intermediate degree of maturity, as it has been already working several years in different quality improvement plans. Additionally, it is also willing to carry out a medium level effort and this is why it decides to adopt for the self-assessment activity the tool called "portfolio".

[Insert Table 1 about here]

The portfolio is made of a conjoint of 32 documents, one for each subcriterion of the model. In these documents it is described each one of such sub-criteria with their strong points, areas to approach, etc. The portfolio allows checking the current strategy and to develop improvement plans for the whole organisation.

Since the implementation of the EFQM model, the CPT carries out two assessments based on portfolios in which the personnel of the center has actively 
participated. It is in February 2005 when the CPT decides to start its third selfassessment by taking advantage of an ongoing personnel-training process about the EFQM model. The self-assessment is carried out during three months and using a self-assessment matrix for CPT centers. Such a matrix, called ALFA II-0180-A comes from the project ALFA, which was born to define an homogenous system for assessing the quality of continuous education based on the EFQM model for both Europe and Latin America. Seven universities (3 from Latin America and 4 from Europe) participated in such a project.

From this last self-assessment comes the first strategic plan of the CPT. Almost all the members of the CPT participated in the self-assessment of each of the defined EFQM model criteria. The levels used in the self-assessment matrix are shown in Figure 1.

[Insert Figure 1 about here]

Hence, there is a numeric matrix where the rows represent each one of the individuals and the columns represent each one of the sub-criteria. The data obtained from the matrix defined in the ALFA project show the scores of each one of the individuals versus each of the criteria and sub-criteria of the defined EFQM model. Each one of the individuals of the center assessed from 1 point to 5 points each one of the sub-criteria in the matrix obtaining then a matrix of 41 rows by 23 columns. Besides, there is a new matrix of 41 rows by 5 columns, one for each one of the model criteria, where the score of a criterion is obtained from adding the values of its subcriteria.

It is also represented the distribution of each of the groups of the CPT regarding both the criteria and the sub-criteria. Each one of the individuals is inside one of the next 11 groups: Own titles (OT), specific training (ST), economic 
management (EM), classrooms, enterprises, surveys and certificates (SC), projects (PR), informatics (INFORM), marketing, design and quality.

\section{Phase 2: Application of statistical data analysis techniques}

The main objective of the PCA is to reduce the dimensionality of a data set constituted by a high number of interrelated variables in order to obtain a few new variables that will contain a great part of the data set variability. The new variables obtained are named latent variables or principal components and are lineal combinations of the original variables and orthogonal among them (Jackson, 2003). Due to such an orthogonal nature, each direction in the new space describes a new source of variation among the samples. In this work it has been built a matrix in which the variables correspondent to the valuations of the model's criteria and the sub-criteria are the variables whereas each of the organisation's individual are the rows. In order to evaluate the different points of view regarding the organizational vision that the different internal departments or groups do have, the technique of supplementary variables representation has been used. This technique calculates the mean of the scorings of the individuals of a determined group within the space generated by the PCA. The deviations from the mean are represented with the distance to the center.

\section{Phase 3: Analysis of results obtained in the Phase 2}

A) Global analysis of the 5 criteria

For the principal component (PCs) analysis, two PCs have been retained, the $\mathrm{PC} 1$ and the PC2, as they together explain as much as $87 \%$ of the total variance of the original data. SPAD v.6 program has been used for analyses

As it can be seen in Figure 2, all the criteria are located in the positive area of the $\mathrm{PC} 1$, what indicates that there is a positive correlation between them. This means 
that the surveyed personnel allocated, generally speaking, either high scores or low scores in all the criteria. This characteristic is known as the "size effect" (Peña, 2002). Then, people allocating higher values in the questionnaire are located at the right hand side of this axis whereas the other people with low values are located at the left hand side. In this sense, it is possible to observe that the individual "p15" is the one that has allocated the highest sores to the criteria. On the other hand the individual "p1" is the member of the organisation that has given the lowest scores to the criteria. The label for the criteria has been: C1 (leadership), C2 (politic and strategy), C3 (people), C4 (alliances and resources) and C5 (Processes).

[Insert Figure 2 about here]

The second component, PC2, shows that the criterion C3 (people) keeps a opposite position that the criterion 1 (leadership) and the criterion $\mathrm{C} 2$ (politic and strategy). Additionally, the criteria C4 (alliances and resources) and C2 (politic and strategy) are in an intermediate position. The near position of the criteria $\mathrm{C} 1$ (leadership) and C2 (politic and strategy) represents that they keep a high positive correlation and, at the same time, both criteria show a negative correlation with the criterion C3 (people). Then, it is possible to conclude that the surveyed usually gives similar scores to the criteria $\mathrm{C} 1$ and $\mathrm{C} 2$, and opposite to the $\mathrm{C} 3$. Those surveyed people located in the positive part of this axis have allocated higher values to the criterion $\mathrm{C} 3$ and lower values to the criteria $\mathrm{C} 1$ and $\mathrm{C} 2$, and vice versa for these people located in the negative part of the axis.

B) Analysis of people grouping according to the 5 criteria

Looking at both Figure 2 and Figure 3, it is possible to observe the distribution of people and working groups, respectively, within the two axes. The analysis carried out is next presented. 
[Insert Figure 3 about here]

It is necessary to point out the position of 3 individuals that can be easily distinguished from the rest: "Pa", "Mo" and "Al". "Pa" and "Mo" are the center director and sub-director respectively. Both of them have provided pretty similar scores to the criteria, allocating scores near to the mean of the rest of individuals. This behavior can be explained in the perception that they share of the centre regarding each of the criteria. Then, they consider themselves promoters of all the actions related to leadership, definition of the mission and vision, definition and implementation of the center politic and strategy, as well of the establishment of relationships with the individuals of the organization. Additionally, they are very involved in the processes and in the continuous improvement of the center. Then, they share a very similar vision of the CPT, as reflected in Figure 2.

On the other hand, the person "Al", who does not carry out his work in Valencia but in another city outside is located at the left hand side of the axis. This shows that he has allocated much lower scores to the criteria than both "Pa" and "Mo". This may be due to the fact that he is not daily present in the work environment of the CPT headquarters. Therefore, he might not be very involved with the activities of the center. "Al" together with "p1" is the individual that has allocated the lowest scores to the criteria.

Figure 3 represents each one of the groups in the factorial axis. Such a representation is obtained as the average of the scores of the members of the group in the survey.

Regarding the groups, it is necessary to point out that "Rooms" and "Economic management" are the two groups with the highest scores in the 5 criteria. Further, the group of "Rooms" is over the C5, "Marketing" over the C1 and C2. 
Regarding the group "Rooms" this may be perfectly due to the fact that the individuals inside this group follow very structural and rigid procedures. Then, they are very involved in carrying out processes for the group's good daily results and in controlling their work.

The group "Marketing" is located very near to the C4 (alliances and resources). Additionally, its work in the center implies a direct relationship with all the groups around the center, as these apply for its services to the CPT. Besides, the co-ordinator of this group keeps an important activity regarding the identification of new alliances and searching of resources to increase, between others, customer satisfaction.

The group of "Economic management" is located near to the criteria $\mathrm{C} 1$ and $\mathrm{C} 2$, being an important support to the rest of the groups. This is due to the tasks that it carries out daily, which are usually related to legislation and internal normative of the university. The group is constituted by highly experienced workers, whose average time in the center is sensibly higher than in those of the rest of the groups.

The other groups are located at the left hand side in Figure 3 and it is possible to differentiate three sets of groups:

The first set is formed by the groups "surveys and certificates", "enterprises" and "design and quality". These groups are very closed to the center by which their scores are near to the average of all the people. They are groups that carry out effective work daily, being compromised with the quality and improvement activities developed in the centre. Additionally, its co-ordinators are very close to the CPT board. Those groups have positively evolved within the last years. The group "surveys and certificates" is one of the groups that more have improved regarding methodologies applied to raise the effectiveness in the daily work as well as in the 
improvement of control and management tools. It is possible to add that the group "design" is highly linked to the "Marketing" one, as they share co-ordinator.

The second set is constituted by the groups "own titles" and "specific training" and they are quite close to the groups of the previous set even though they have clearly allocated lower scores to the criteria $\mathrm{C} 1$ and $\mathrm{C} 2$ and higher scores to the $\mathrm{C} 3$. The co-ordinators of these two groups keep a close relationship with the people working with them, who are mostly very experienced administrative workers. Then, they work in a very structured and organised manner. In other meetings, surveys, etc these workers have not valued positively neither the criteria $\mathrm{C} 1$ nor the $\mathrm{C} 2$, especially regarding the knowledge of the strategic plan, the participation in the definition of communication plans, motivation issues and personnel recognition.

However, the greatest difference takes place in the third and last set of groups constituted by the groups "projects" and "informatics", which are the groups that have provided the lowest scores to the criterion C3. Individuals of other groups form the group of "informatics", and it is constituted especially by technical programmers. There is not a clear perception of group as they work in different groups of the CPT. They hold regular meetings to plan the tasks in the rest of groups. It is possible to affirm that they do not receive the necessary training for the successful development of their tasks. Additionally, their work is required immediately without a previous planning in most of the cases. On the other hand, the group of "projects" has experimented over the last years an increment in their workload. The $90 \%$ of its members is hired under limited contracts and therefore there is a different work environment. The members of this group do not have the security of holding a lifetime contract, as more of the other CPT members, and this contributes to a 
continuous flow of workers incorporating and leaving the group. Those are the most relevant causes that justify the low scores in the $\mathrm{C} 3$.

In this way, after analysing the data of all the individuals it is possible to group them into six differentiated groups, as shown in Figure 4.

[Insert Figure 4 about here]

Figure 4 shows a dendograme obtained from a cluster analysis, which is a multivariate technique that allows classifying observations into homogeneous groups based on the variables observed for this specific individual. In this case, the individuals are members of the organisation whereas the variables are the valuations of the EFQM model criteria. The dendograme shows the six groups found. As a measure of the method's internal distance the square Euclidean distance has been used, and the Ward method as grouping method.

It is possible to affirm that the grouping is very heterogeneous, being very difficult to classify them in groups in this first iteration.

C) Analysis of each criterion

After having analysed each criterion globally, an individual analysis of each criterion and correspondent sub-criteria was carried out. The addition of the scores of the sub-criteria of each criterion results in the position occupied by such a criterion. Since the explanation of all the five criteria presented would be too long for this paper, two criteria has been chosen to be fully explained: C1 (leaderships) and C3 (people).

- Analysis of the criterion C1 (leadership).

The sub-criteria of this criterion are the following:

sla: Existence and development of both the mission and vision of the CPT.

s1b: Management system based on the continuous improvement. 
slc: Implication of the responsible people of the center with interest groups.

s1d: Motivation, support and recognition of personnel.

Figures 5 and 6 show the representation of both the individuals and the groups regarding the above sub-criteria.

[Insert Figure 5 about here]

[Insert Figure 6 about here]

As observed in Figure 5, all the sub-criteria are located in the positive part of the first axis (PC1). This indicates that there exists positive correlation between all of them. In this way, the surveyed people allocate, generally speaking, either high or low scores to all the sub-criteria. Then, the people of the organisation allocating the highest scores to the $\mathrm{C} 1$ will be located at the right hand side of this axis whereas the lowest scores will be at the left part.

The axis of the PC2 shows the sub-criterion "s1a" as the one with highest score in the projection over such an axis, being the "slc" the one with the lowest score. The sub-criterion "sla" does shown a no-correlation versus the "s1c" and a nearly no-correlation between "s $1 \mathrm{~d}$ " and "s1c".

Regarding the individual $s$, it is possible to observe that the individual "p9" is the one that has allocated the highest score to the criteria and the individual "Al" the one allocating the lowest scores. The individual "p9", alike the individual "Al", is a technician that has scored the sub-criteria "sla" and "sld" very high in comparison with the rest of the people in the organisation. On the other hand, the individual "Al" has scored the lowest values for reasons previously commented.

The CPT director is located very near to the axis of the sub-criterion "sla", having scored it very high. This is due to the fact that the director was one of the most influent and involved people in the definition of the mission and vision of the CPT. At 
the same time, the sub-director is located between the sub-criteria "s $1 b$ " and "s $1 \mathrm{~d}$ ". It is necessary to point out that the sub-director is the person that offers more support to people of the centre regarding labour and even personal issues and therefore her scores to "s1d" are high. Additionally, she also supports the continuous improvement process of the CPT, being one of the first in introducing quality issues and involving to all the personnel.

The second component represented in Figure 5 in the vertical axis shows that the sub-criteria "s1a" keep a contraries position related to "s1c" and "s1b" whereas the "s1d" has got an intermediate position. The closeness of "s1c" and "slb" represents that they hold a high positive correlation and the opposite position (negative correlation) with "sld". Then, the surveyed people usually give similar scores to "s1b" and "s1c" and opposite scores to "s1d". Those people inquired in the positive part of this axis have given the highest scores to "sld" and, simultaneously, lowest ones to "s1c" and "slb". On the other hand, the individuals located in the negative part have experimented an opposite behaviour. In this case the individual "p12” versus "p16" and "p36”.

In Figure 6, regarding the working groups located in the axis of the $\mathrm{PC} 1$, the groups of "rooms" and "economic management" are the ones that have allocated the highest scores to the sub-criteria. On the other hand, the group "projects" is the one allocating the lowest scores. The rest of groups are located between these groups.

Regarding the group "projects", it is possible to affirm that its lowest punctuation may be due to a lack of cohesion among the group individuals with the rest of groups and with the center's board. 
The axis of the PC2 shows the group "rooms" as the one with the highest score in the projection over such an axis. On the other hand, the groups "surveys and certificates" and "enterprises" are the ones with the lowest scores.

- Analysis of the criterion C3 (people).

The sub-criteria of this criterion are the following:

s3a: Proper personnel planning

s3b: Development of people's capacity

s3c: Involvement and compromise of the personnel

s3d: Existence of a dialogue between the personnel and the organisation

Figures 7 and 8 show the representation of both the individuals and the groups regarding the above sub-criteria.

[Insert Figure 7 about here]

[Insert Figure 8 about here]

The PC1 axis shows two of the sub-criteria "s3a" and "s $3 b$ " in the right hand side of the graphic, and the other two sub-criteria "s3c" and "s3d" in the left hand side. This means that the individuals of the organisation have scored higher the "s3a" and "s3b" than the "s3c" and "s3d". Therefore, "s3a" and "s3b" are positively correlated as well as "s $3 \mathrm{c}$ " and "s $3 \mathrm{~d}$ " and between the two sets of sub-criteria maintain a negative correlation.

It is necessary to comment that, in the last surveys made by the CPT personnel, they have expressed their dissatisfaction regarding the dialogue between them and the organisation.

Regarding the individuals it is possible to observe that the individual "p35" has allocated the highest scores to the sub-criteria "s $3 a$ " and "s $3 b$ " being also the one allocating the lowest score to the sub-criteria "s3c" and "s3d". Individual's "p3" 
results are just opposite to these ones, as it can be seen in Figure 7. In other words, those people that have positively valued the existence of a proper personnel planning and development of people's capacity have also scored low the implication and compromise of the personnel and the existence of a dialogue between the organisation and the personnel. Hence, it is important to highlight that the CPT board encourages the realisation of courses for developing the personnel capacities. Additionally, there is a sub-set of people who are currently under a accreditation process and they therefore undertake a higher number of these courses than the rest of the personnel.

The PC2 axis shows the sub-criteria at its bottom, being therefore all of them correlated (size effect). From these, the "s3c", "s3d" and "s3b" have got the same or a very approximate value respecting the PC2 axis, being the value of the "s3a" a bit lower.

Regarding the work groups (Figure 8), in the PC1 axis, the groups located at the right hand side of the axis such as "Enterprises" or "Marketing" have scored higher in the sub-criteria "s3a" and "s3b". Additionally, these groups have also scored lower to the sub-criteria "s3c" and "s3d". Exactly the opposite happens with the groups located at the left hand side of the axis such as "quality" or "own titles".

The PC2 axis shows the group "Projects" as the one of lower punctuation in the projection of this axis, versus the groups of "rooms" and "own titles" that have achieved higher scores. Respect to the group "projects" it is necessary to point out that, due to daily work and to the high amount of projects the CPT deals with yearly, personnel values very low their planning due to different motives such as lack of personnel. 


\section{Conclusions}

The EFQM model has been widely applied to all types of organisations. Despite the criticism that the model has received during the last years regarding its methodology and applicability, it is a solid self-assessment model than can be used for a wide range of finalities within an organisation. The proper application of such a model can be laborious and take quite a lot time. Nevertheless, the model provides very useful and valuable information that can lead to improve multiple lacks and gaps of the existing processes at the same time that measuring both the processes and the whole organisation performance. Then, in order to optimise the efforts necessary when applying the EFQM model, it is necessary to maximise the information coming from such implementation. The EFQM elements are configured in a way that, once the model has been implemented, will provide structured information that can be treated through statistical methods. At the same time, this analytical process points out latent or hide information referent to diverse ambits of the organisation, which might be very useful to support decision-making processes.

Under this perspective, a case study carried out at the Permanent Training Center of the Polytechnic University of Valencia in Spain has been presented. It has been described the procedure followed to use the information resulting from applying the EFQM excellence model with the finality of analysing the perception that the members of this organisation hold regarding the business vision. The analysis has been developed applying multivariate statistical techniques, more concretively the principal components analysis (PCA). As it was justified in the paper, the PCA enables to extract relevant information of the vision that the members of the organisation have got regarding the business vision. With this technique it is possible 
to evaluate the relationship between the perception of the criteria according to the different groups or individuals. PCA provides a wider general vision than the one provided by the uni-variant analysis, which allows to make decisions more objectively.

One of the most important tasks carried out has been the analysis and interpretation of the obtained results after applying PCA. In this sense, this activity has to be always made together with the organisation's expert personnel. Such work force is the one that facilitates the interpretation of the results, providing directions to the analytical valuations coming from combining both the EFQM model and the PCA. In the case study presented a work team constituted by the organisation board and the responsible of each group of people analysed was formed. The analysis allowed to make decisions that have improved the organisation processes, affecting to different types of resources (human, material, economic, etc) at different levels (strategic, tactic and operative).

Regarding future research work, the authors are currently carrying out other analysis in which they apply structural models based on a PLS-path modelling approach in order to identify other factors that complement the ones of this study.

\section{References}

Anderson, T.W. (1984). An introduction to multivariate statistical analysis. New York: John Wiley \& Sons.

Baxter, L. F. \& MacLeod, A. (1999). Measuring business excellence: the case of leadership. Management Services, 43 (7), 14-17.

Bou-Llusar, J.C., Escrig-Tena A.B., Roca-Puig, V. \& Beltrán-Martín, I. (2005). To what extent do enablers explain results in the EFQM excellence model?: An empirical study. International Journal of Quality \& Reliability Management, 22 (4), 337-353. 
Calvo-Mora, A., Leal, A. \& Roldán, J.L. (2006). Using enablers of the EFQM model to manage institutions of higher education, Quality Assurance in Education, 14 (2), 90-122.

Dale, B.G., Zairi, M., Van der Wiele, A. \& Williams, A.R.T. (2000). Quality is dead in Europe - Long live Excellence. True or false?, Measuring Business Excellence, 4 (3), 4-10.

Eskildsen, J.K., Kristensen, K. \& Juhl, H.J. (2001). The criterion weights of the EFQM excellence model, International Journal of Quality \& Reliability Management, 18 (8), 783-795.

Farrar, M. (2000). Structuring success: a case study in the use of the EFQM Excellence Model in school improvement, Total Quality Management, 11 (4/5/6), 691-676.

Franceschini, F., Galetto, M. \& Maisano, D. (2007). Management by measurement. Designing key indicators and performance measurement systems, New York: Springer.

Hides, M.T., Davies, J. \& Jackson, S. (2004). Implementation of EFQM excellence model self-assessment in the UK higher education sector - lesson learned from other sectors, The TQM Magazine, 16 (3), 194-201.

Jackson, J.E. (2003). A user's guide to principal components. New Jersey: WileyInterscience.

Kaplan, R.S. \& Norton, D.P (1996). Using the balance scorecard as a strategic management system, Harvard Business Review, January-February, 75-85.

Li, M. \& Yang, J.B. (2003). A decision model for self-assessment of business process based on the EFQM excellence model, International Journal of Quality and Reliability Management, 20 (2), 164-188.

Martin-Castilla, J.I. \& Rodriguez-Ruiz, O. (2008). EFQM model: Knowledge governance and competitive advantage, Journal of Intellectual Capital, 9 (1), 14691930.

McAdam, R. \& Welsh, W. (2000). A critical review of the business excellence model applied to further education colleges, Quality Assurance in Education, 8 (3), 120-130.

Olve, N., \& Wetter, M. (1999). Performance Drivers: A practical guide to using the balanced scorecard, New York: John Wiley \& Sons.

Peña, D. (2002). Análisis de datos multivariantes, Madrid: McGraw-Hill.

Ruiz-Carrillo, J.I.C. \& Fernandez-Ortiz R. (2005). Theoretical foundation of the EFQM Model: the resource-based view, Total Quality Management, 16 (1), 31-55. 
Rusjan, B. (2005). Usefulness of the EFQM Excellence Model: theoretical explanation of some conceptual and methodological issues, Total Quality Management, 16 (3), 363-380.

Santos-Vijande, M.L. \& Alvarez-Gonzalez, L.I. (2007). TQM and firms performance: An EFQM excellence model research based survey, International Journal of Business Science and Applied Management, 2 (2), 21-41.

Tari, J.J. (2006). An EFQM model self-assessment exercise at a Spanish university, Journal of Educational Administration, 44 (2), 170-188.

Timm, N.H. (2002). Applied multivariate analysis. New York: Springer,

Waugh, R.F. (2002). Academic staff perceptions of administrative quality at universities, Journal of Educational Administration, 40 (2), 172-188.

Wongrassamee, S., Gardiner, P.D. \& Simmons, J.E.L. (2003). Performance measurements tools: the balanced scorecard and the EFQM Excellence Model, Measuring Business Excellence, 7 (1), 14-29.

Yang, J.B., Dale, B.G. and Siow, C.H.R. (2001) Self-assessment of excellence: an application of the evidential reasoning approach, International Journal of Production Research, 39 (16), 3789-3812. 
Table 1

\begin{tabular}{|c|c|c|c|c|}
\hline 4 & $\begin{array}{l}\text { ORGANISATION } \\
\text { MATURENESS }\end{array}$ & - $\quad$ Proper questionnaire & $\begin{array}{l}\text { - Portfolio } \\
\text { model }\end{array}$ & $\begin{array}{l}\text { Simulation, } \\
\text { presentation to the } \\
\text { prize }\end{array}$ \\
\hline & $\begin{array}{l}\text { INTERMEDIATE } \\
\text { LEVEL }\end{array}$ & $\begin{array}{l}\text { - Questionnaire and } \\
\text { work meetings } \\
\text { - } \quad \text { Proper improvement } \\
\text { matrix and work } \\
\text { meetings }\end{array}$ & $\begin{array}{l}\text { - Portfolio } \\
\text { model }\end{array}$ & $\begin{array}{l}\text { - } \begin{array}{l}\text { Simulation, } \\
\text { presentation to the } \\
\text { prize }\end{array} \\
\text { - } \begin{array}{l}\text { Portfolio model and } \\
\text { work meetings }\end{array}\end{array}$ \\
\hline & $\begin{array}{l}\text { STARTING THE } \\
\text { ROAD TO } \\
\text { EXCELLENCE }\end{array}$ & $\begin{array}{ll}\text { - } & \text { Elemental } \\
\text { questionnaire } \\
\text { - } & \text { Standard } \\
\text { improvement matrix }\end{array}$ & $\begin{array}{ll}\text { - } & \text { Standard } \\
& \text { questionnaire }\end{array}$ & $\begin{array}{ll}\text { - } & \text { Very detailed } \\
\text { questionnaire } \\
\text { - } \quad \text { Customised matrix }\end{array}$ \\
\hline & & LOW EFFORT & $\begin{array}{c}\text { INTERMEDIATE } \\
\text { EFFORT } \\
\end{array}$ & HIGH EFFORT \\
\hline
\end{tabular}


Figure 1

\begin{tabular}{|c|c|c|c|c|}
\hline Level 1 & Level 2 & Level 3 & Level $\mathbf{4}$ & Level 5 \\
\hline $\begin{array}{c}\text { Quality depends } \\
\text { on the personal } \\
\text { initiatives }\end{array}$ & $\begin{array}{c}\text { Start to the } \\
\text { processes }\end{array}$ & $\begin{array}{c}\text { Process } \\
\text { Management }\end{array}$ & $\begin{array}{c}\text { Evaluation } \\
\text { and improvement } \\
\text { of the processes }\end{array}$ & $\begin{array}{c}\text { External } \\
\text { orientation toward } \\
\text { quality }\end{array}$ \\
\hline
\end{tabular}


Figure 2

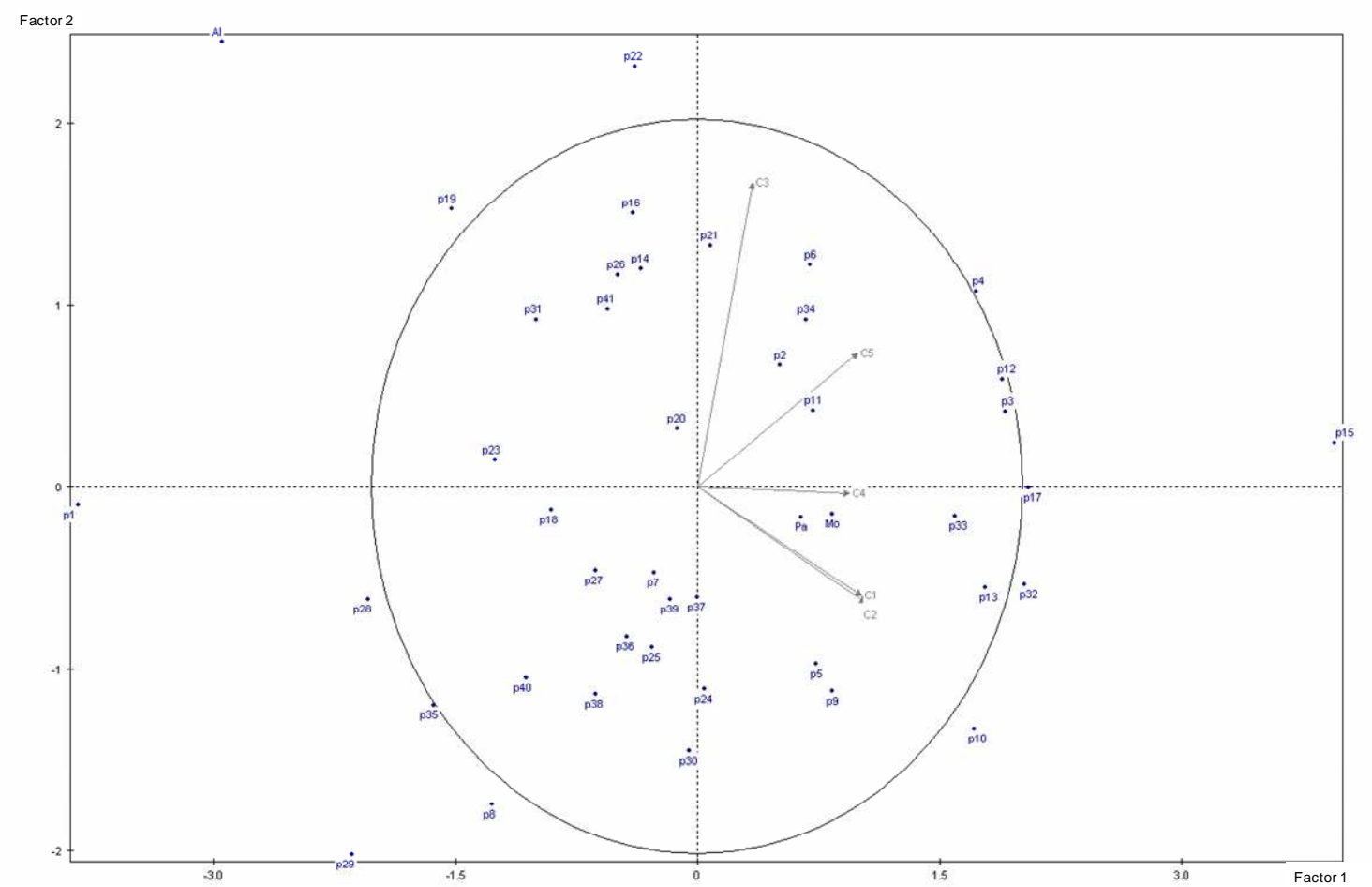


Figure 3

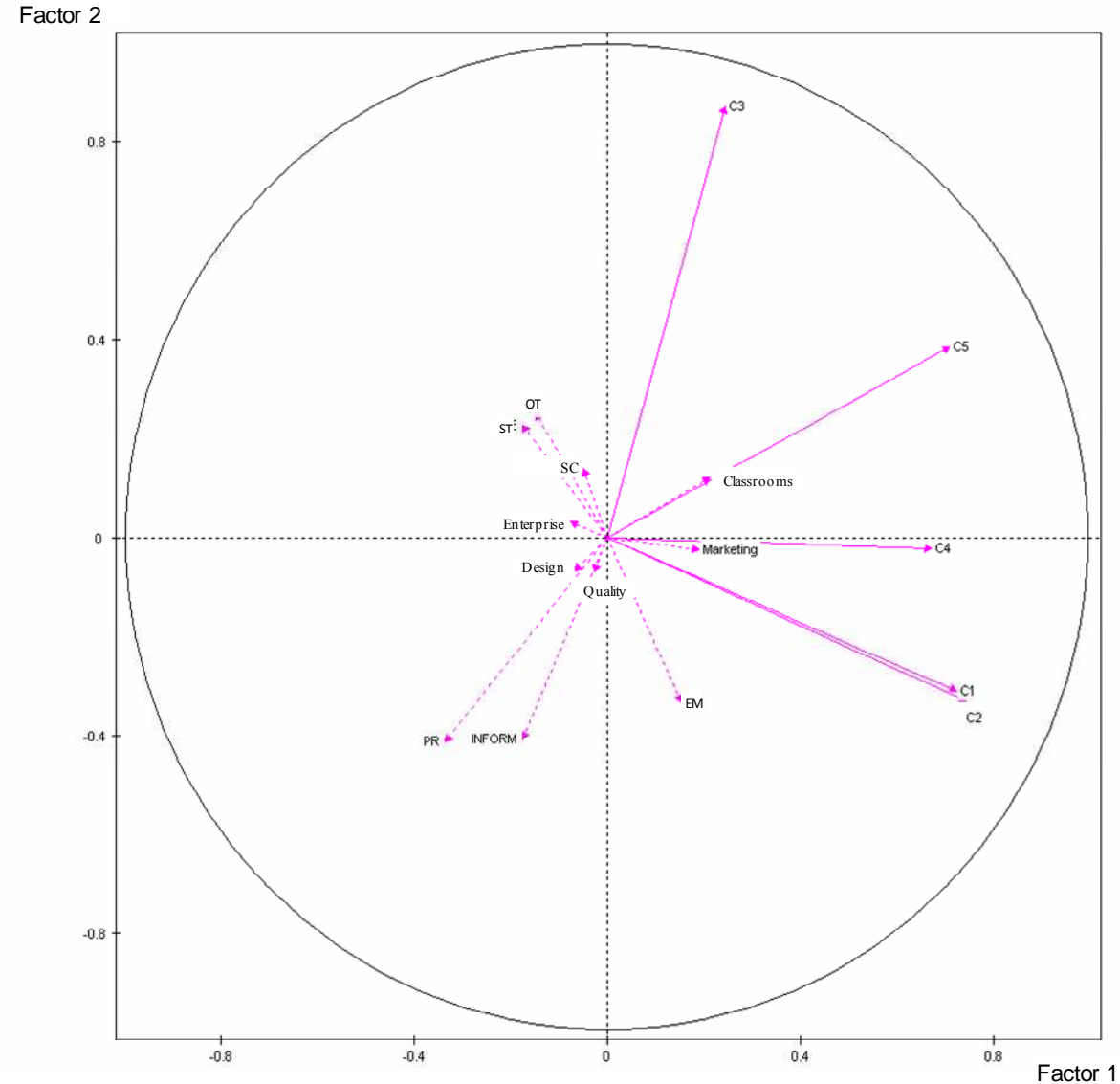

Figure 4

Direct hierarchical classification

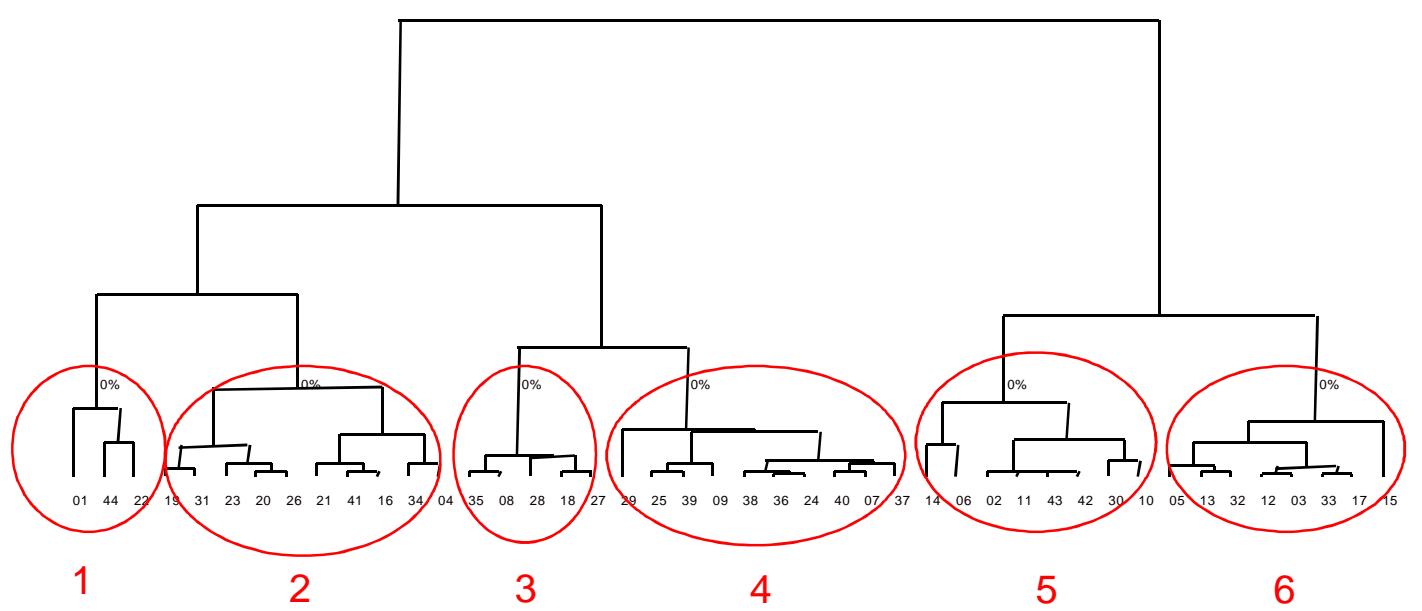


Figure 5

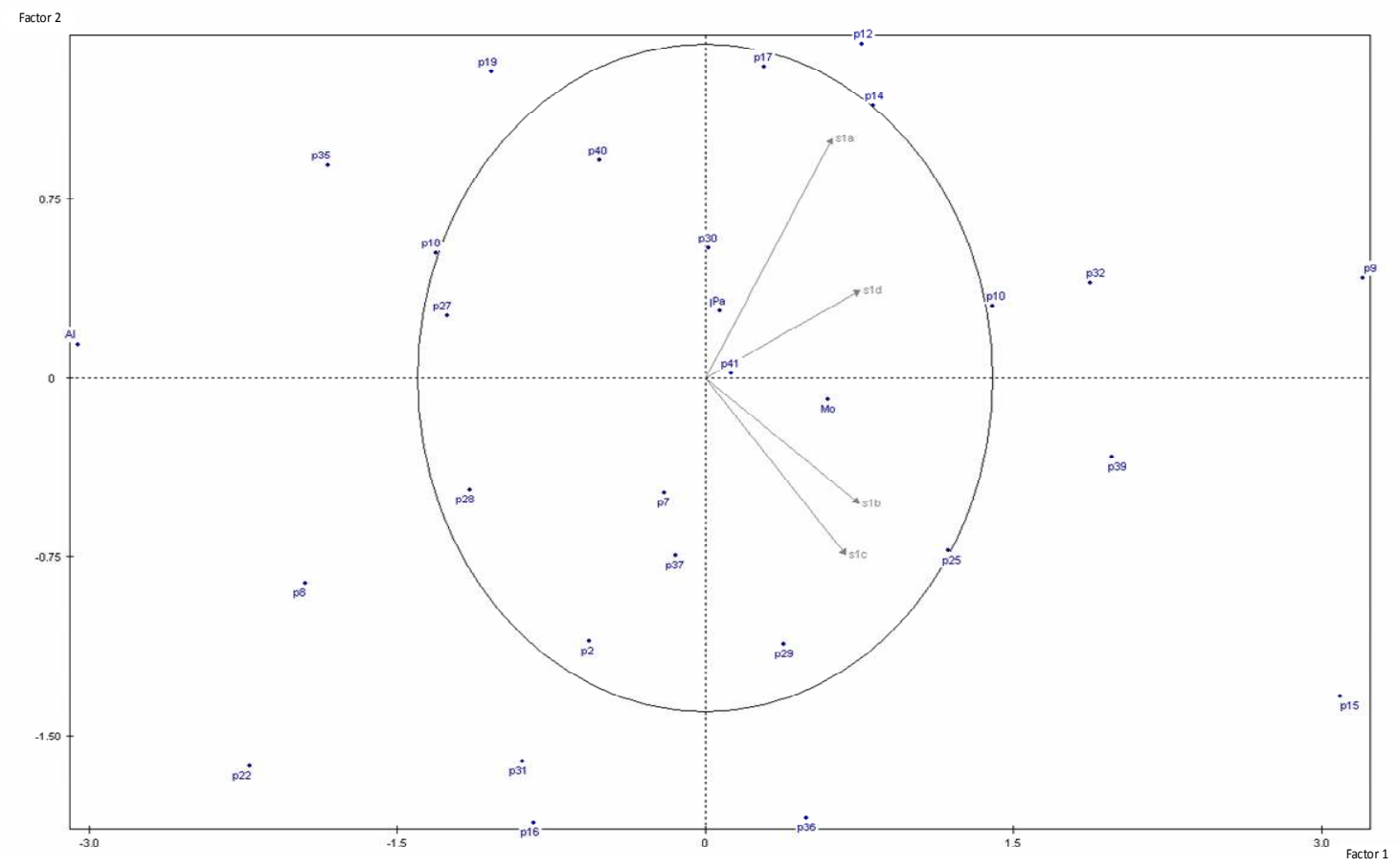


Figure 6

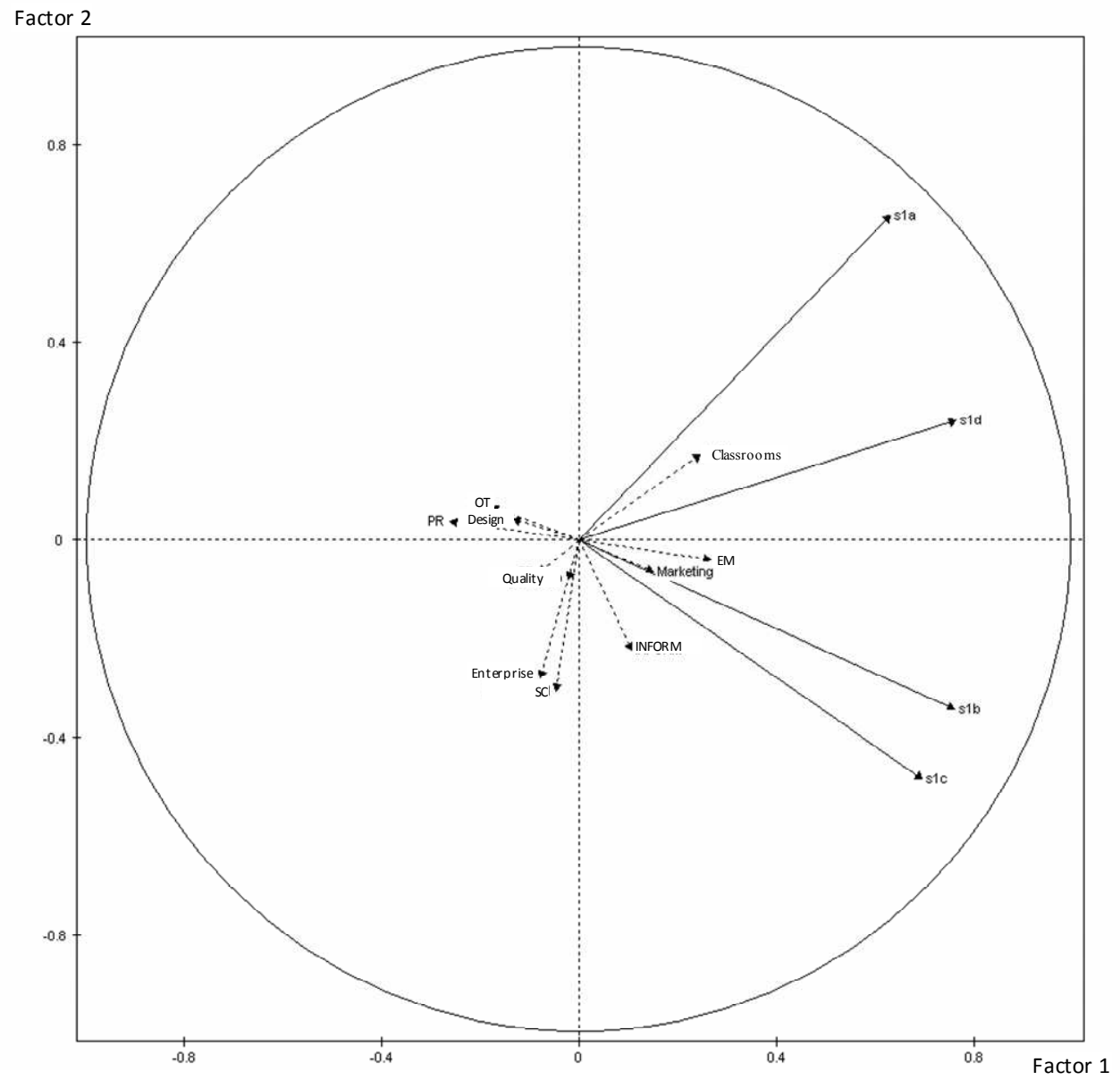


Figure 7

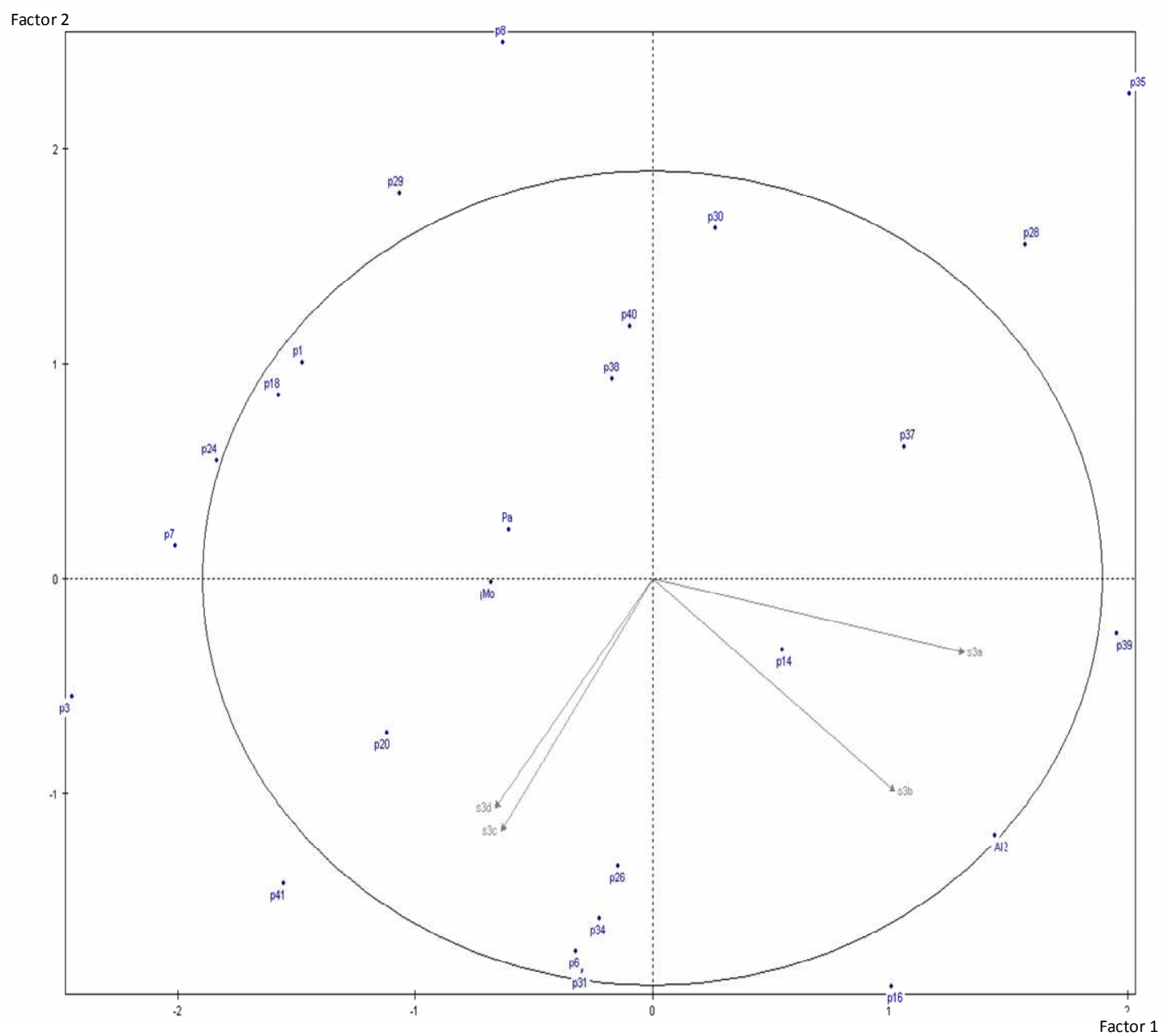


Figure 8

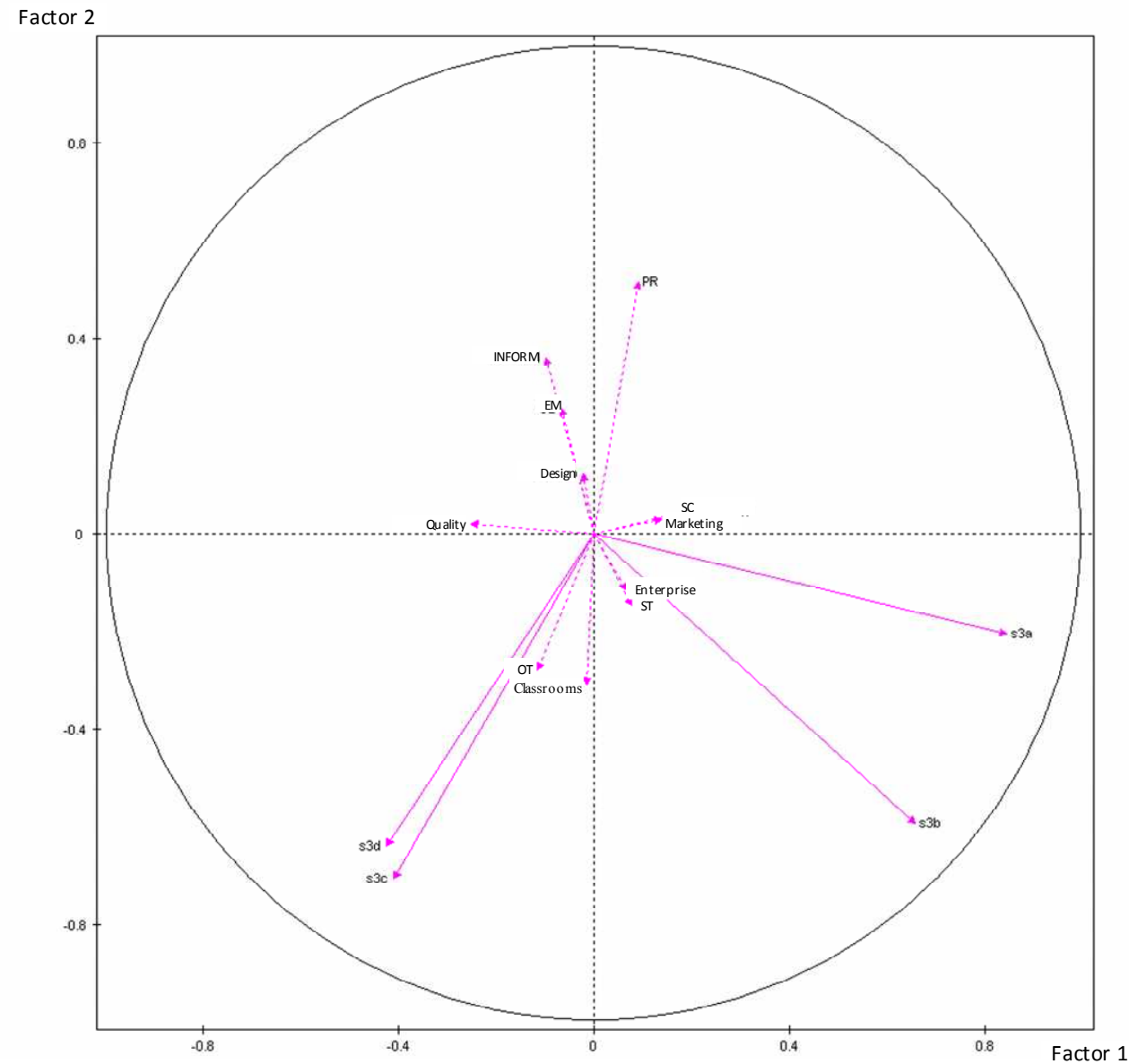

